\title{
USING ANALYTIC HIERARCHY PROCESS (AHP) FOR ASSESSMENT OF NATIONAL HEALTH INSURANCE SCHEME SERVICE DELIVERY IN NIGERIA
}

\author{
Paul Olanrewaju OLONADE \\ Department of Business Administration, \\ University of Lagos, Nigeria. \\ E-mail: olonocome@yahoo.com \\ Sulaimon Olanrewaju ADEBIYI \\ Department of Business Administration, \\ Federal University of Agriculture Abeokuta (FUNAAB) \\ E-mail: lanre18april@gmail.com
}

\begin{abstract}
National health insurance scheme (NHIS) was implemented in Nigeria like many other policies of government aimed at enhancing citizen welfare, but the healthcare services received by patients from healthcare providers as well as the healthcare needs of the workers whom were compel to make the contribution (percent of their monthly income) as matter of law are different in various dimension. This make the situation to be multicriteria and complex, thus, the need for evaluating NHIS service delivery in Nigeria from the perspective of workers of various organisations that has contributed and enjoys the services as patient using analytic hierarchy process. In simplifying the problem, an hierarchical model was built for assessing healthcare service delivery of NHIS in Nigeria with the determinant of good/effective health care service delivery as the goal, while five criteria; protect of families from the financial hardship; rising cost of healthcare services; equitable distribution of healthcare costs, services delivery and healthcare services efficiency, also four levels of hospital were identified (FMC, general hospital, primary healthcare and private hospital) to serve as the alternatives. A pairwise comparison was carried out using the criteria and its sub, in relation to the goal and alternatives in order to enhance effective policy decisions that affect citizens' life positively. The results of the AHP survey reveal the priorities of the workers (patients) towards NHIS criteria so as to help at achieving effective healthcare service delivery in Nigeria as well areas that require overhauling in order for the insurance scheme to achieve its stated objectives. This study provides empirical based for assessment of NHIS implementation in Nigeria through it quantification of workers perception of the policy and the utilization of resources.
\end{abstract}

Keywords: AHP, NHIS, Healthcare, service delivery, patient, hospitals. 